\title{
Development of Platform for robotic control by smartphone
}

\author{
Leonardo S. de Almeida (IC), Conrado L. Silva (IC), João V. V. d'Abreu (PQ)
}

\section{Abstract}

The advent of smartphones in the last times makes them an attractive way to robotic control, mainly in Educational Robotics (ER). This paper talks about the development of a Platform, a hardware to control robotics devices using a mobile phone by Bluetooth.

Keywords: Educational robotics, Arduino, Mobile control.

\section{Introduction}

Robotics is a topic that can conciliate the abstract with the concrete as computer instructions command the environment around him. When applied on educational works show herself like a ludic and practical way to interdisciplinarity and in transmit of values like responsibility, creativity and problem resolution skill, ${ }^{1,2}$.

The smartphones are familiar equipment for almost the entire population, so the use of these devices makes the robotics more attractive in educational environment.

\section{Results and Discussion}

The "brain" of platform, shown in Image 1, is an Arduino UNO, a much applied microcontroller in robotics because he doesn't demands expertise in electronic or programming.

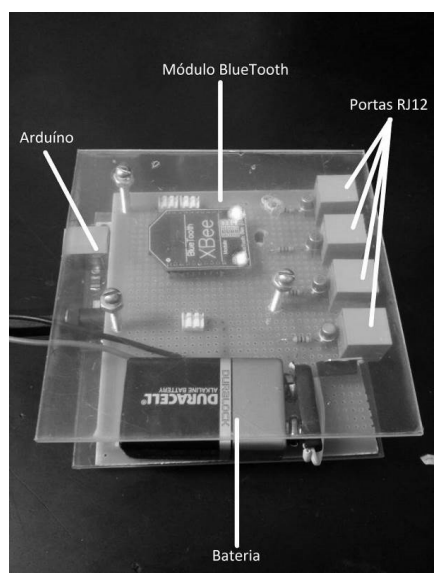

Image 1. Platform developed in his final stage

To make the communication between Arduino and cell phone, by Bluetooth, was employed a XBee module that receive an wireless information and transmit to controller, by serial. This means that module works like a bridge between the microcontroller and the module.

Aiming the possibilities of control for the largest numbers of robots, the developed hardware has standard gates with RJ12 connector, i.e., just needs that the actuator (motor, valves, pumps, etc.) has a pair of this connector to make a link with platform.

This tool follows the correspondent logic: a data is sent from smartphone (with the app Bluetooth RC Controller), received by $\mathrm{XBee}$ module and interpreted in Arduíno. If that information is "turn on" some actuator linked a gate of platform, the microcontroller's correspondent output turns high. If that information is "turn off" the actuator, the Arduino's output turns low.

An example of application for this platform consists on control from toy car movement. For this purpose the car has 2 motor, one for traction and another for the direction which both are connected at platform gates.

\section{Conclusions}

Because of popularization of smartphones in entire world, the usage of these devices in robotics can make her cheaper and attractive, a first step to familiarization of science.

Like said, the developed platform, shown in this paper, has a lot of applications because of her standard link, depending of the finality and the actuator that is connected in her gates. To control a robot or any robotic devices needs only connect his motors in this tool.

\section{Acknowledgement}

To Núcleo de Informática Aplicada à Educação (NIED) for provide the local to implementation and project tests, to our mentor for all support, correction and incentives and to all people that helped direct or indirectly the development of this project.

\footnotetext{
${ }^{1}$ Trentin, Marco A. S., Pérez, Carlos A. S e Teixeira, Adriano C. A robótica livre no auxílio da aprendizagem do movimento retilíneo. Campinas, 2013. Artigo WRE 2013. Universidade de São Paulo - USP..

${ }^{2}$ D'Abreu, J. V. V, Garcia, M. F. Robótica Pedagógica e Currículo. São Bernardo do Campo, 2010. Universidade Estadual de Campinas - UNICAMP.
} 